on the subject of "The Interaction of Technologies", the first prize of 250 guineas has been awarded to Lr. J. Rose, principal of Blackburn College of Technology and Design, and the second prize of 200 guineas shared between Professor J. A. Allen, professor of chemistry at the University of Newcastle, New South Wales, Australia, and Mr. D. J. Simpson, deputy librarian at University of Manchester Institute of Science and Technology.

The Hugh L. Dryden Memorial Fund is being created at the request of friends and professional associates of the late deputy administrator of the National Aeronautics and Space Administration, it has been announced by Mrs. Dryden, Mr. James E. Webb, administrator of NASA, and Dr. Frederick Seitz, president of the National Academy of Sciences. Shortly after Dryden's death last December, a group of his closest associates presented to the Academy a private fund together with a request to support the creation of a committee of distinguished individuals to devise a lasting memorial to their late colleague. After some deliberation, the committee decided that the long association of Dryden with the Academy, and his many contributions to science, engineering and national goals in aeronautics and space, might be most appropriately recognized by the provision of a long-needed auditorium in Washington, to be constructed as an integral part of the main building of the Academy on Constitution Avenue. The funds raised will also be used to establish an honorary award in recognition of outstanding contributions in a professional field closely associated with Dryden's career.

THE seventh seminar on "Electrochemistry", arranged by the Central Electrochemical Research Institute, is to be held at Karaikudi during December 27-30. Further information can be obtained from Dr. C. V. Suryanarayana, Convener, Seventh Seminar on Electrochemistry, Central Electrochemical Research Institute, Karaikudi-3, India.

CoRrigendum. In the article entitled "Resistance of Fish Embryos to Chronic Irradiation", by V. M. Brown and W. L. Templeton (Nature, 203, 1257; 1964), microcuries ( $\mu \mathrm{c}$.$) should read millicuries (me.) in Tables 3$ and 4.

Corrigendum. In the article entitled "Manganese-54: Fractional Distribution in Wheat and Occurrence in Other Foods" by Doris C. Sutton and John J. Kelly, which appeared on p. 1081 of the March 12,1966, issue of Nature, the final sentence which reads ". . . is approximately 4,000 pe. ..." should read "is approximately $4 \times 10^{6}$ pc. ..."

Corrigendum. In the article entitled "Low-temperature Fluorography induced by Tritium-labelled Compounds on Thin-layer Chromatograms", by Dr. U. Lüthi and Prof. P. G. Waser, which appeared on p. 1190 of the March 20, 1965 , issue of Nature, the caption of Fig. 2 should read “. . Solvent: acetic acid/hexane/diethylamine (75.5/ $17 \cdot \dot{5} / 5) "$.

Corrigrndum. In the captions of Figs. 1-3 of the communication entitled "Radiation Protection by an Auxin Analogue $\beta$-2,4,5-Trichlorophenoxyethanol, in $C 57 B L / 6 J$ Mice exposed to Cobalt-60 Gamma Radiation", by Dr. R. D. Schultz, Mr. C. W. Steers and Dr. D. Norman, which appeared on p. 207 of the April 10, 1965, issue of Nature, " $\beta-2,4,5$-trichlorophonoxyacetic acid" should road " $\beta-2,4,5$-trichlorophenoxyethanol".

Erratum. In our issue of August 6 we incorrectly attributed the $\$ 5$ million grant from the Sloan Foundation to Stanford University rather than the California Institute of Technology.

\section{COMPUTERS IN THE HOME}

\section{By our Special Correspondent}

\author{
Dartmouth, New Hampshire, September 29.
}

THE newest status symbol in this isolated university town, best known for the success or at least the roughness of its football team, is the possession of a personal computer console-something on which to work in the evenings and something on which the children can do their homework. These are only some of the benefits of a multiple access computer, provided with a simple computer language and accessible to several institutions at the same time. Computer consoles are boing scattered about the neighbour. hood to satisfy a great variety of needs or potential needs. Ton of them are housed in a students' computing room, carved by means of temporary partitioning out of a kind of barn in which young men (there are no women) are still to be heard playing pool and table tennis, and the mathematics department has been able to arrange that all its students should go through a course on computer programming. Specialist academic departments, such as economics and engineering, have their own consoles on the spot. Within the past year, remote terminals have also been installed at a number of schools in New England, and have been enthusiastically welcomed by teachers of mathematics. Finally, as is now customary, the Dartmouth computer can be linked by telephone circuits with others of the same kind at a dozen locations in the United States.

This network of computer terminals is of interest and importance because it offers a way of testing the claims of the enthusiasts for multiple access systems. The best known of the experiments in this direction is perhaps the MAC system at M.I.T., but the 25 consoles linked to that system tend to be used by academics seeking the same kinds of services, frequently the retrieval of information. At Dartmouth, diversity is obtrusive. The belief that multiple access computers can cater for such a diversity is one of the chief arguments of those who urge their advantages.

Whether the computer system being developed for use by British universities and research councils should consist of multiple access machines is still, for example, an open question, and will not be resolved until there is at least some working experience with the computer to be installed at the computing centre at Edinburgh.

The system at Dartmouth is based on a computer built by the General Electric Company, with assistance from the National Science Foundation. Software for the system has been developed by a team at Dartmouth under Professor John Kemeny (Mathematics), Professor Thomas Kurtz (Director of the Computation Centre) and Professor Myron Tribus (Dean of Engineering). Its principal feature is a computer language called BASIC, which-according to its authors-differs from those like FORTRAN in being designed specifically for a computer working on time sharing principles. In practice, BASIC seems also to be even simpler to use, though it is probably also somewhat limited in scope.

The mechanics of time sharing in the Dartmouth computer are accomplished by means of a piece of switching equipment, originally developed for quite a different purpose, which is connected both to the main computer and to a disk storage system in such a way that signals from up to 35 different consoles can be dealt with so as to present a uniform flow of instructions to the computer. The switching equipment ensures that no single console has access to the computer for more than 5 seconds at a time. If a console should present the system with a piece of work which cannot be dealt with in such a time, the work in progress at the ond of five seconds will be discharged on to a disk store and then reworked when the 